\title{
A propósito del bicentenario: Ambigüedades en la independencia de Arequipa
}

\author{
About the bicentennial: Ambiguities in the independence of Arequipa
}

\author{
Mario Zapata Delgado
}

\section{RESUMEN}

Esta investigación tiene como finalidad apreciar las contingencias y ambigüedades de la independencia en Arequipa, donde la elite y la plebe no estaban establecidos en una gran brecha económica, más bien era difusa en términos económicos, mas no así dentro de una hegemonía y subordinación basado en conceptos de honor para el rico, y honradez para el pobre, en ese entramado se dan dos etapas fundamentales, el ingreso de Pumacahua en Arequipa -1814- y la jura de la independencia en 1825, la historiografía menciona la capacidad patriótica del arequipeño a partir de algunos personajes, lo cual creemos falso ya que tanto la plebe como la elite no quisieron la independencia, solo buscaban algunas reformas que mejoraran su situación en el mundo urbano; donde si hay una presión por una transformación más profunda es en la zona rural. La metodología que hemos utilizado es la historia regional; además las fuentes de archivo utilizadas pertenecen a los repositorios del Archivo Regional de Arequipa, Archivo Arzobispal de Arequipa y el Archivo municipal. Esta investigación nos presenta algunos resultados en torno a la ambivalencia de los grupos elite-plebe plurietnica, además que la fisonomía geográfica y las distancias permiten apreciar una actividad más particular que nacional, unido comercialmente con el alto Perú. Permite apreciar que finalmente la independencia de Arequipa mas fue un mandato de Sucre mediante un comunicado y publicado en el diario Primavera de Arequipa, que un patriotismo señero de la población, ello no inhibe que hubo algunos intelectuales, sacerdotes y población que sí estuvieron de acuerdo con un cambio radical.

Palabras clave: Historia regional, Independencia; sociedad, ambigüedades sociales.

\begin{abstract}
This research aims to assess the contingencies and ambiguities of independence in Arequipa, where the elite and commoners were not set in a large economic gap, rather it was diffuse in economic terms, but not so within a hegemony and subordination based on concepts of honor and honesty to the rich for the poor, in this network are two key steps in entering Arequipa Pumacahua -1814 - and the oath of independence in 1825, mentions historiography arequipeño patriotic capacity from some characters, which we believe false as both the mob and the elite did not want independence, only some reforms sought to improve their situation in the urban world, where if there is pressure for a deeper transformation is in the rural area. The methodology we used is the regional history, plus archival sources used belong to repositories Arequipa Regional Archive, Archive Archbishop of Arequipa and the Municipal Archives. This research presents some results about the ambivalence of elite-mob groups multiethnic, and geographic features that allow distances appreciate a more particular national activity, coupled with the high Peru commercially. Lets see that finally the independence of Arequipa more Sucre was mandated by a statement published in the newspaper and Spring of Arequipa, a landmark of the population patriotism, it does not inhibit that there were some intellectuals, priests and people who did agree with a radical change.
\end{abstract}

Keywords: Regional History, Independence, society, social ambiguities.

\footnotetext{
${ }^{1}$ Universidad Nacional San Agustín de Arequipa, correo electrónico: felipemariozapatadelgado@yahoo.com.pe
} 


\section{INTRODUCCIÓN}

Antecedentes, las investigaciones que sobre la independencia del Perú se han realizado pueden ser enfocadas en cuatro momentos: la primera, tiene como objetivo el fortalecimiento de la peruanidad, los escritos de Mariano Felipe Paz Soldán (1888), German Leguía y Martínez (1972); Vickuña Mackena (1971), pasando por la generación del 900, la obra prolífica De La Puente y Candamo (2013), conocida dentro de la historiografía como tradicional; el marco que engloba esta postura es la idea de la construcción de la nación peruana, el mestizaje y la capacidad de generar un patriotismo acendrado, reflejado en símbolos y representaciones; una segunda etapa sobre este proceso se da en la década del 70, a propósito del sesquicentenario y la producción de la colección Documental de la independencia del Perú (CNSIP, 1971-1976), es la escisión de una historiografía del Perú como nación reflejada en la obra de Bonilla y otros autores (1981), que a diferencia de la historiografía anterior, nos dice que la independencia del Perú fue concedida, que el Perú nunca fue homogéneo y que la idea de mestizaje es una creación de un discurso legitimador del statuo quo dominante, y que durante todo el periodo colonial estuvo desbordado por diversos levantamiento y asonadas contra el antiguo régimen; luego surge una nueva perspectiva a partir de la idea e implementación de la modernidad al interior de la monarquía hispánica la que finalmente lleva a la desintegración de este mundo hispanoamericano (1992); y es a partir de esta propuesta y tomando en cuenta el balance y las perspectivas del Bicentenario en Latinoamérica se han realizado estudios o reeditado una profusión de investigaciones en torno a la independencia en este sentido es aleccionador el planteamiento de Timothy E. Anna (2003), resalta el régimen español en nuestro país: la pobreza. Desvanecer la ilusoria idea de riqueza del virreinato peruano, porque hubo crisis en la economía colonial en la etapa final de la dominación hispánica. Sumado a la escasez de la mano de obra, la ausencia de buenos caminos y comunicaciones, lo limitado del capital invertido y el estancamiento del comercio debido a las constantes guerras. Fue en ese mar de contradicciones en donde los protagonistas resolvieron el destino histórico nacional, donde se enfatizó que las revueltas regionales fueron más contra Lima que la corona, en 1814, (Zela, Paillardelle, Angulo, Crespo), Brian Hamnett propone que no existe una evidencia clara $\mathrm{y}$ conclusiva de que las "naciones incipientes estaban luchando contra un sistema imperial injusto para emanciparse" (2011, p. 372), es decir no hubo un intencionalidad liberal y menos independentistas por parte de los patriotas que "se trajeran abajo 300 años de dominio español", sino que -después de las independencia- terminó de desmoronarse la idea de la monarquía en el Perú ya en una avanzada república.

Justamente esta investigación busca a través de la historia regional embarcarse en una mirada local de la independencia en Arequipa dentro de una perspectiva global, básicamente porque creo que las formas historiográficas anotadas, en su construcción imprimen una visión vertical es decir la explicación de la totalidad y partiendo de los hechos más connotados. Es por ello que buscamos la mirada provinciana, local, cotidiana y real en torno a los diversos grupos sociales y sus acciones sin descuidar la mirada global; para lo cual hemos tomado dos etapas muy marcadas en nuestra historia de la independencia regional la de 1814 con Pumachua y Angulo y la de 1821 y 1825 , en que recién se jura la independencia. Considero que esa mirada es necesaria para comprender que esta juramentación en un balcón por San Martin el 28 de julio de 1821, ¿tuvo algún efecto en un marco nacional? pienso que no fue así. Es por ello que he planteado los siguientes objetivos: La independencia de Arequipa tuvo dos fases la primera con Pumacahua y Angulo entendida como formación de las juntas de gobierno que finalmente no cuajo y una segunda fueron los españoles y criollos que a partir de una herencia y todo lo que significó, no se animaron a jurar la independencia en 1821 sino más bien dilatarlo hasta 1825, ello explicaría que hubo una formación económica articulada a diversos ámbitos de la sociedad que fortaleciera el statuo quo de la sociedad arequipeña en vez de una incierta libertad expresada en un discurso histórico y patriotero; y finalmente la sociedad arequipeña estaba marcadamente formada por grupos sociales, ambiguos y difusos ya que la campiña que constituía gran parte de la economía no permitió la formación de una elite muy rica, lo cual conllevo a situaciones de diferencias no muy definidas en los sectores sociales, pero sutilmente esto nos puede hacer parecer que los grupos no tuvieran diferencias profundas, no, a pesar de las brechas económicas mínimas existió una hegemonía de poder.

MATERIAL Y MÉTODOS: planteamiento metodológico pertenece a la historia regional expuesta por Alice Cardoso Vera y que responde a una interpretación política estrecha de la identidad regional, utilizado como sinónimo de regionalización. Las fuentes primarias de esta investigación se encuentran en los repositorios del Archivo Regional de Arequipa; Archivo Arzobispal 
de Arequipa y el Archivo Municipal de Arequipa. En nuestras pesquisas, el repositorio documental del Archivo Arzobispal fue fundamental, detectamos la existencia de un proceso contra Mariano José de Arce (citado por Porras); dos procesos seguidos contra el Dr. Don José Manuel Fernández de Córdova Cura de la doctrina de Salamanca; según el dato siguiente: Archivo Arzobispal de Arequipa; Protocolo de 1816 - 1820; Causas Civiles 1814; Proceso José Manuel Fernández de Córdova Cura de Salamanca: 09-09 1816 fs. 1-4, Además hallamos otro proceso por fuga de enemigos fechado en 1823, Causas Civiles. Archivo Arzobispal de Arequipa. También sobre la sociedad y plebe plurietnica se ha trabajado en los repositorios del Archivo Regional de Arequipa, a saber: ARAR, Intendencia Administrativo 20-I1803, Don Pascual Vargas cacique de Santa Marta, presenta las dificultades entregar los Reales Tributos. De igual manera los documentos del: 22-VII -1785 20-VI 1780. Se hizo la búsqueda en el Archivo Municipal de Arequipa encontrando documentación sobre donaciones a la causa fidelista en la diversas asonadas que se dieron en el sur peruano: AMA LAC 1813-1815 y 1815-1820, entre otras fuentes consultadas.

\section{RESULTADOS}

\section{AREQUIPA EN EL ESCENARIO DE LA INDEPENDENCIA.}

La fisonomía de Arequipa puede ser definido como una pintura al fresco de aquellas campiñas catalanes o de Córdova, donde hasta hoy día no pierden sus colores y su bucólico romance con el pasado, Felipe Bauza repara

su planta es admirable por estar en llano y a ésta ventajosa disposición acompaña la hermosura de las casas que siendo todas de piedra y abovedadas, ofrecen a sus habitantes viviendas cómodas y a la vista un aspecto agradable por el universal cuidado e inclinación de aquel vecindario para conservarse con aseo y decencia (Zegarra 1973,p.19).

Alberto Flores Galindo menciona.

"Arequipa no ha sido territorio de grandes haciendas. La predominancia de la pequeña y la mediana propiedad es una. Característica del paisaje agrario arequipeño, desde los tiempos coloniales hasta la actualidad. La gran propiedad, en todo caso, aparece como excepción en medio de un paisaje definido por las "chacras" (1977,p.23)

Víctor Andrés Belaunde veía heredades más bien austeras y no un propiedades muy lucrativas de grandes beneficios y fortunas de esta sociedad enclavada en la sierra interandina, decía:

"No tuvo Arequipa...ni la jerarquía social constituida por las propiedades extensas, y -ni- las pingües encomiendas, característica de otras ciudades del Perú" (Belaunde, 1957, p.71). Evidentemente, las grandes propiedades, salvo a excepción de valles como Tambo, o tierras de la familia Goyeneche en las cercanías de Arequipa, no estuvieran ni en la campiña, ni en los valles, sino más bien, en las alturas de Puno y el Cuzco. La riqueza de la clase alta arequipeña va a reposar en los territorios de estos dos departamentos.

En cuanto a la fidelidad, esta fue muy grande por ejemplo los blasones que ostentó como leal, fiel y fidelísima al rey de España, la cual es reconocida, por cédula del 5 de diciembre de 1805. Entonces ¿cuál fue la participación de Arequipa en la independencia?, según la historiografía, esta fue más rural que urbana, bástenos señalar: Arequipa no fue teatro de ninguno de los movimientos libertarios, ni de ella tampoco surgió el apoyo efectivo para los que estallaron en otras partes, salvo en la revolución de Pumacahua cuando ingreso a la ciudad, contando con el fervoroso aporte de algunos intelectuales y religiosos, en cambio a los realistas le apoyo la elite arequipeña y los funcionarios más representativos, un caso claro es que Arequipa había enviado pertrecho de guerra al Alto Perú y se anunció la llegada de Pumacahua, ésta busco con mucho esfuerzo armar el ejército de Picoaga y Moscoso, y cuando este estuvo en campaña llegando a llevar víveres y aguas "corrieron al campo.....y ofreciéndoles -las damas- ellas mismas...heroísmo que obligo a Moscoso a ponerles un lazo de cinta blanca en el brazo para distinción del patriotismo con que defendían su suelo y su derecho (FloresGalindo, 1977, p.55).

Sucre en 1823 sufrió la deserción de sus elementos en pro de la corona, Gonzaga de la Encina decía de sus párrocos que eran fundamentales "Los sentimientos de fidelidad hacia nuestro amado rey y la detestación del sistema revolucionario" (Zegarra Meneses, 1973,p.20)

Arequipa siempre se consideró goda o chapetona; el lema "Arequipa Ciudad blanca" está referido a tener una población reconocida como "blanca" mayoritariamente. Don Gil de Taboada y Lemus en un censo (1796), realizado en el cercado, encontró 22,207 españoles; 5,929 indios, 4,908 mestizos.

Flores atisba, que "La mancha india", característica del surandino tiene su excepción:

aparece una ciudad predominantemente occidental y española: Arequipa. A la predominancia de españoles en Arequipa colonial, se va a añadir las tempranas migraciones de ingleses y franceses, posteriormente españoles y árabes, que aunque se producen en escaso número, incrementan a la clase dominante arequipeña la que por cierto tampoco fue muy numerosa. (Flores-Galindo, 1977, p. 56)

Ello indicaría una proclividad y fidelismo a la corona, pero este problema es más complejo y vale la pena un acercamiento. Entonces el proceso de independencia fue, en Arequipa un despertar, pero es 
necesario entremezclarnos en la complejidad de sus protagonistas, en esta aclaración la elite está fuertemente arraiga a una lealtad a ultranza lo demuestra las múltiples donaciones, prebendas y regalías que permanentemente entregaron en apoyo a la causa realista: Veamos algunos donativos que hizo la ciudad de Arequipa frente a asonadas en la Paz, donde la lealtad, de sus ciudadanos es por demás sugerentes.

"En cumplimiento a lo acordado en la acta 3-V-1804 sobre los negocios tristes de la ciudad de la Paz y donativo... al Señor Virrey del Reino, y a la que ordene en la materia para que se le dar cuenta por expreso como unánimemente se acordó; pues todos lo obrado es solo, con el objeto de que las cosas están preparadas para aprovechar los instantes y obras sin demora si es preciso y se resuelve el auxilio.

- El Exmo. Sr Maraus de Aviles veinte mil pesos 20,000- El V. y Cardo quatro mil pesos 4,000 El Sr. Alcalde de Segundo Voto Coronel Don Domingo Tristán 300......" - El Sr. Dn. Juan de Goyeneche contestando a la pregunta que quedo a dar el día de ayer sobre el donativo ofrece costear veintidós soldados por el termino de un mes y a su hijo el alférez de caballería Dn. Juan Mariano de Goyeneche sin sueldo ni bagaja, para que los señores comandantes, con respecto a su calidad y circunstancias lo destierren en lo que tuviesen por conveniente con lo cual se concluye este cabildo....".

Demuestra largamente la actitud de la elite, de apoyo al mantenimiento del statuo quo. Mas no fue así en algunos sectores, intelectuales y algunos sacerdotes, como el Cura Centeno, Fernández de Córdova, Mariano José de Arce, Luna Pizarro y otros.

Todas estas muestras, nos permiten apreciar varios elementos en este proceso.

- La lealtad de la elite urbana arequipeña a la corona.

- La proclividad de algunos sectores populares, intelectuales y sacerdotes a favor de la causa patriótica.

- Una ideología del mantenimiento del statuo quo

- La "riqueza" austera de la elite.

- La insurgencia rural.

No nos olvidemos que en el sur andino Arequipa, jugó un papel fundamental y al ser un bastión realista contrarrestaba la insurgencia de Puno y Cusco: Pero aún en contra de la geografía, la región llegó a conformarse y la ciudad de Arequipa, a medio camino entre el puerto y el altiplano, ciudad de costa y de sierra, a la vez, pudo establecer su hegemonía sobre los valles costeños, el altiplano de Puno y los territorios altos del Cuzco, principalmente. La definición de la hegemonía arequipeña será un proceso largo, gestado desde los tiempos coloniales y realizados sólo a fines del siglo pasado.

\section{SOCIEDAD PLURICULTURAL}

A diferencia de otras poblaciones del virreinato, la ciudad de Arequipa estaba compuesta principalmente por españoles y mestizos. En los alrededores mismos de la ciudad los indios escaseaban. Echevarría y Morales atribuyen el fenómeno a una temprana migración a los Collaguas. Según un testimonio de 1795 - la revisita de Joaquín Bonet - más de 36,000 habitantes conformaba la población arequipeña, de los cuales 22,712 eran españoles $(62 \%) ; 4,908$ mestizos (13\%) y 5,099 indios (14\%). El porcentaje restante estaba conformado por negros y mulatos. Tadeo Haenke observaba que,

hay gran número de familias nobles, por haber sido alli donde más han subsistido los españoles, tanto por la comodidad del temple y la abundancia de los víveres, como por la oportunidad del comercio por medio del puerto que sólo dista veinte leguas. (Flores-Galindo, 1977). Similar al censo realizado por el Virrey Don Gil de Taboada y Lemus. De acuerdo con "La Relación del intendente Salamanca....", no abundan los mendigos, ni los indios forasteros (Fisher, 1968).

Creemos que se dio un fenómeno muy peculiar en la sociedad plurietnica de ese entonces, a saber: a) La Hegemonía Ideológica, de los grupos dominantes, la cual nos sirve para explicar los mitos sociales por lo que este grupo tenía el control social a través de la coerción y el consentimiento, como infieren Tord y Lazo (1981). Es decir la Hegemonía señala la capacidad de la clase dominante de imponer su visión del mundo y sobre la sociedad, en este decurso historiográfico encontramos puntos de vista muy variados como explicar la sociedad pre independiente desde la república de Indios y españoles; sociedad de castas, estamentos, capas y culturas; basada en jerarquías; una aristocracia vinculada a la península; élites provinciales y una masa pauperizada (plebe, castas, población flotante e indios), mientras que los estudios regionales de Fisher, Lynch, Flores Galindo y Chambers, enfocan realidades particulares que indican temores de las elites provinciales con respecto de Lima y a su vez representan un cuadro de sociedades ambiguas.

Intentaremos un acercamiento a esta difusa sociedad, sabiendo que la población era mayoritariamente blanca, es posible que el Censo de Taboada se haya inflado con mayor proporción de "blancos", al considerar a mestizo y mulatos de piel más clara, como españoles; se atribuye el crecimiento de la población blanca entre otros motivos el de evadir impuestos.

Chambers utiliza la categoría étnico-estamental para ingresar a la población urbana, advirtiéndonos que 
era reducida o difusa la distancia entre la elite y la plebe, por lo que no y había demasiado control por parte de las autoridades civiles, pero si celo eclesiástico en uso de costumbres y creencias (2003, p. 8-9)

Siendo el concepto de "Honor" y el reconocimiento de la elite, distinto, en la plebe arequipeña, ya que no era entendida como "obediencia", "respeto", "Lealtad", de actitud inferiorizante. Sino más bien la noción de "honor" es de "cuasi-igualdad", sumado a ello el factor étnico (casta) que al contrario denota una caracterización de castas más fluida y difusa que vertical: el mestizo, cholo y mulato pasaban por blancos; incluso hubo juicios de "limpieza de sangre" para probar su blancura. Otro factor fue el que la elite arequipeña era reducida por tanto el temer de la plebe era mínima, quizás porque esta élite estaba formada por medianos propietarios, comerciantes, artesanos, etc. Distinto a Lima que si era conformada por una aristocracia muy fuerte.

Pensamos que estas características peculiares estimularon a que se creara un nuevo sentido del "honor" basado en la virtud y no en las jerarquías de "superioridad", estimulados por la mínima diferencia de "castas" (étnico), el honor era entendido como código social. La nobleza protege su "linaje", la plebe protege su conducta honesta: "Hombre de bien".

Durante la colonia, como se ha visto el código de honor es jerárquico y vinculado con la monarquía, en cambio en el proceso de independencia se va desvaneciendo, y su legitimidad va ser cuestionada, aperturandose las ideas de igualdad y libertad, en algunos sectores dándose una interpretación del honor basado en el "merito individual", en vez de privilegio hereditario.

\section{b) el honor de los grupos}

La sociedad arequipeña, en la independencia, tuvo una ideología de honor más inclusiva: la ciudadanía, hombre de bien; en vez de linaje y privilegio, es decir un sistema estamental y de castas muy ambiguo y difuso, siendo no determinante la elite y su ideología dominante, más bien por el contrario se asimila nuevos conceptos de honor.

Veamos, al no tener, la élite arequipeña, grandes títulos ni grandes propiedades, más bien reducida y de medianos recursos, como observo Flora Tristán y Humboldt, entonces los elementos de coacción son mínimos e incluso desparecen, dice Chambers "ni siquiera habían guardianía civil para reprimir los desórdenes de la plebe". No se temía "a los de abajo", existe el "honor popular" $(2003,12)$ influenciado por la elite mediatizados por presuntos rasgos "igualitarios", entonces la sociedad plurietnica puede ser comprendida por: a) Elite regional: formada por autoridades, alto clero, oficiales militares, burocracia administrativa, los vecinos nobles, caciques y principales, terratenientes, comerciante y mineros, arrieros, conductores de comercio,

b) Plebe plurietnica, formada por pequeños comerciantes el bajo clero, artesanos, individuos de oficio, jornaleros, las servidumbre de negros e indios.

Por supuesto los parámetros teóricos terminan siempre a veces siendo un mal espejo de la realidad. $\mathrm{Vg}$. El desplazamiento de indios, que conformaban la plebe hacia sectores de la elite, era posible (caciques), el haber estudiado una profesión y sumado a que reuniese las condiciones requeridas bastaban: "La casta no era impedimento para integrar la élite, muchos hacendados propietarios eran mestizos, que incluso podían ocupar cargos público (Tord y lazo,1981, 391)

En parte este asidero es correcto, pero tenemos serias dudas respecto de lo que se entiende por casta, ya que Tord opina que las castas son relativas, por lo que un negro podía acceder adquirir tierras y romper su status y acceder a otro, creemos que no fue tan fácil, porque la estratificación por castas no solo es étnicoracial sino también cultural. Esta situación era asumida por el blanco-europeo, y este sector, (albión), el color no tenía ninguna relevancia, sino contaba con una economía holgada, era común encontrarse con españoles y criollos definidos como plebeyos y hasta asimilados en condición servil, ya que como lo hemos visto la sociedad arequipeña urbana era más fluida que fija, diferente en la zona rural, esta al ser menos fluida y más fija, los elementos de coerción de la elite rural fueron más notorios; señala Scarlet O'phelan tanto los partidos de Condesuyos, Caylloma y Majes eran proclives a la insurgencia, corroborado por las fuentes documentales de los archivos, y es el caso del Cura de Salamanca, y de muchos otros más, por ejemplo. Además es necesario anotar otra característica, mostrada por Bernard Lavalle; los movimientos en el surandino fueron más en contra de Lima que España, la cual se resumía a una pugna entre la elite provinciana vs. Aristocracia limeña; pugna entre criollos provincianos y españoles; por equiparidad de oportunidades. La historia de Arequipa y del Cuzco permanecía más relacionada con los territorios de las actuales repúblicas de Bolivia y la Argentina, que con Lima o la costa norte. Los desiertos y los malos puertos - esas constantes de la costa sureñaalejaban a Arequipa de Lima. De aceptar las observaciones del virrey Gil de Taboada y Lemos, a pesar de esto había existido un importante comercio entre Lima, Arequipa y Tarapacá. Pero, a medida que transcurría el tiempo, este comercio parece que fue disminuyendo. Con el desarrollo del puerto de Arica, 
o mejor dicho, con su recuperación, se volvieron menores los lazos con la capital. "En adelante será naturalmente menor la exportación", dice Lequanda refiriéndose a Lima, "por cuanto no se surten por el Callao las provincias de Arequipa, respecto a que, como se tiene insinuado, se abastecen por el puerto habilitado de Arica".

\section{LA ELITE SOCIAL}

A inicios del siglo XIX la situación política de Arequipa ante la emancipación del dominio español, estaban involucrados en sus valores fidelistas, ya el Rey Carlos III la designo como la muy fiel y leal de todo el Virreinato peruano después de Lima. Esta situación se hace notar en la colecta masiva del partido de Arequipa a favor del ejército patriota español. Una ciudad que guardaba fidelidad y lealtad a la Corona demostrada con los fuertes donativos que le hacía a su favor. Estas buenas actitudes ayudan sobre todo a los habitantes chapetones de la ciudad de Arequipa, con las oportunidades de adquisiciones de terrenos o favoritismos como en casos civiles de adjudicación de tierras en el tiempo colonial. Al fin y al cabo otorgaban este dinero en condición de préstamo, ya que le será retribuida favorablemente por medio de la corona Real. Entonces, su mayor interés social de los españoles residentes en la ciudad de Arequipa era quedar bien con la corona Real y de esta manera cuidar sus intereses económicos.

La sociedad de Arequipa no era una burguesía tan opulenta y notarial como la de Lima, la cual llego a tener el control del monopolio comercial de España. Debido a que las propiedades que tenían la elite arequipeña no eran igual a la gran elite dirigente de Lima -como vimos líneas arriba-. Además fue en esta capital del Virreinato donde se congregó el monopolio comercial del tabaco, naipes y papel sellado con España, ocasionando graves pérdidas económicamente a los comerciantes del Atlántico.

El linaje, era un requisito indispensable para poder mantener su honor, es por ello que se hace la limpieza o pureza de sangre (dícese a aquellos personas indias que se casaban con los españoles) y deseaban una emergencia social y llegar a ser mestizos, o para evitar el pago de impuestos.

En Arequipa era un sector medio grande de que era importante para los hacendados, comerciantes y profesionales distinguiéndose de los que se ocupan en manualidades denominadas los oficios viles y bajos (Chambers, 1992)

El desorden de la administración judicial fue preocupante para las autoridades republicanas quienes: reorganizaron e hicieron más eficiente el sistema de justicia criminal... con el establecimiento de la Corte Superior de justicia con cuatro vocales que luego se incrementaron a seis, y en 1830 se nombra por la corte un juez para que vea sobre las causas delictivas..." (Chambers: 1992:7)

La fidelidad era indispensable para los colonos residentes en esta ciudad, pero, esta no podía ser eterna; debido a los problemas que pasaba España en Europa con la invasión de Napoleón y que no había un orden administrativo en las colonias americanas además, las nuevas ideas ilustradas que llevaban por el atlántico, vía del contrabando a inicios del siglo XVIII, como la luz, por las rendijas de la carcomida sociedad colonial. Por eso al asumir el cargo de Obispo de Arequipa el Ilustrísimo Sr. Goyeneche en 1819, recomendaba a su párroco, destruir con sus predicas "las ideas, la subversión en que vemos imbuido a muchos con sumo dolor de nuestro paternal corazón." Las ideas que desde 1790 fueron difundidas, cobraron mayor impulso con la fundación de la Academia Lauretana, Seminario de San Jerónimo como semillero ideológico bajo la batuta de Chávez de la Rosa; la aparición de la Tertulia literaria, etc.

\section{I I . L O S C R I O L L O S E N L A INDEPENDENCIA.}

Eran los comerciantes de menores recursos, funcionarios de la orden artesanos prósperos y sobre todo profesionales liberales, maestros e intelectuales; fue este grupo de criollos el que justifico la independencia y le dio forma y coherencia al proceso emancipador (SANTISTEBAN : 1995: 13); por su parte López Soria indica que, eran aquellos criollos que no gozaban de privilegios comerciales, ni habían accedido a los puestos de control de la burocracia colonial, eran artesanos, prósperos funcionarios de segunda categoría, liberales e intelectuales (LOPEZ SORIA : 1982: $95-98$ )

Entonces, los criollos urbanos, fueron aquellos que no tuvieron mucho que ganar con la independencia pero cuando las disposiciones emitidas por la metrópoli se dirigían en contra de sus intereses comerciales, fueron los primeros en salir en protesta en contra de los peninsulares, estos no eran los únicos que lucharon, los indios quienes a consecuencia de la caída de la rebelión de Túpac Amaru, fueron perseguidos, va a ser solviantados sobre todo de las zonas rurales, por algunos sacerdotes para apoyar a los criollos y mestizos en 1814, que coincidían en intereses económicos y políticos. Una expresión de ello fue la Academia Lauretana y la tertulia de Mariano Melgar. (ZEGARRA MENEZES, 1973: 62)

\section{LAS CASTAS.}

Las Castas asociaban en la persona raza y bagaje cultural. Estas cualidades abarcaban muchas cosas como linaje o raza, color de la piel hábitos y costumbres, la tradición social, disposiciones para solo determinados trabajos. En este contexto social todos convenían en la ventaja de ser blancos sea por el tipo de ocupaciones de tenían o por querer ejercer cargos de superioridad el perjurio racial llevaba a los criollos a vanagloriarse, como lo dice un cronista de la época: 


\begin{abstract}
“Odian al español más si se ofrece alegar sobre el lustre y nacimiento no se le escucha otra cosa (que decir), mi padre fue gallego, andaluz mi bisabuelo [..] Soy mas español que los mismos europeos". (LAZO: 1981:361)
\end{abstract}

Los hijos de los chapetones decían esto porque, no querían quedarse atrás, en que siendo sus padres comerciantes y funcionarios de la institución pública, las castas secundarias los vacilaban en dicha forma, es por ello, que decían ser más español que el mismo europeo, para así de esa manera sobresalir su linaje y tener un respeto por los demás (mestizo, indio, negro). Estos son los grupos sociales que le siguen, es por ello que convenía ser blanco en la colonia, porque tenían acceso a trabajos de poca monta como barbero, comerciante, peluquero, abarrotero, etc., actividades que en el tiempo colonial eran de honra y respeto social, pero de sectores bajos, ocupados por las castas; es decir que se tenía abierto todas las puertas para desarrollar cualquier tipo de actividad de lucro.

Es por ello que en la ciudad mistiana el Intendente se inundó con solicitudes quejándose [de que] "ese Vargas los forzaba a pagar tributos"( Chambers: 1991: 157)

ante ello la plebe muy molesta lanzaba imprecaciones porque a pesar de su linaje y ser reputado como honrado y hombre de bien no debieron ser coaccionados a pagar dichos tributos, por ello muchos se hacían los juicios de limpieza de sangre o pureza de sangre para saber o comprobar:

"la descendencia de cristianos viejos, el no tener como tronco de familia a un judío, a un moro o a un converso, el no haber sido penitenciado por la inquisición ni el descender de algún relajado y el no estar mellado por la infamia de la ilegalidad también la carencia de un espíritu cristiano estaban sujetos a la limpieza de sangre" (TORD YLAZO; 1981.T.IV.-371)

Esta limpieza de sangre se dio con más frecuencia a fines del siglo XVIII, donde el dominio español decaía y estaba en auge las ideas liberales o de los ilustrados franceses, es por lo que el indio o mestizo toma hábitos peninsulares como lo que como lo que pasó en la Parroquia de Santa Marta :

...los indios no quieren pagar tributo... por motivo de que estos como Mariano Betanzos quiere volverse Español, ya porque se visten a lo español, ya porque aprenden oficios de españoles, como, barberos, sastres, etc., ya porque tienen el color algo pálido, ya porque se han peinado a la moda, ya porque sus padrinos son españoles, y los hacen bautizar en la catedral, y ya porque se mudan los apellidos de indio, y se ponen los de español. Todos estos abusos es preciso extirparlo de raíz y aplicar a tiempo el remedio correspondiente a fin de que este [se expanda]...porque de lo contrario llegara el día en que no haya indio ninguno, ni menos quien pague el Real tributo como ya se esta experimentando, pues en cada revisita tributaria que se va haciendo se va disminuyendo en este ramo y aunque uno quiere hacer empadronar a los que conocen que son indios; salen estos con que son españoles, y se liberan de la contribución del real ramo con presentar tres testigos pagados y de poca. Consideración para que declare a su favor

Estas limpieza de sangre, como lo indica el cacique Betanzo originó la exoneración del pago del Real tributo por lo que los curas estaban en contra de este tipo de situaciones, ante esto, Betanzos denuncia y hace un informe a su Majestad para que se cumpla con la lo que se ha dispuesto dar la décima parte de lo producido. Esta situación era desesperante para los colonos peninsulares porque son ellos quienes se benefician con ser leales a la corona mientras que el lucir al tipo peninsular de los mestizos, cholos y algunos indios (funcionarios); los condujo a tener casi iguales derechos de los chapetones, es por eso que se desarticula socialmente las normas de la sociedad española. Incomodando a los españoles y caciques que eran los encargados de cobrar este tributo real para la corona, pero en el fondo la situación era diferente, porque los caciques no cobraban para la corona sino que era para ello mismo, hasta llegar al extremo de la violencia y amenazas como esta:

“... Dn Pascual Vargas, Cacique de recaudación del Tributo de Forasteros me exige el cumplimiento del tributo constituyéndome por indio sin haber nacido yo con este gravamen pues mis padres y abuelos jamás han sido tributarios (y lo peor que)... llevado del odio que me tiene el dicho cacique por haberme en tiempos pasados seguido una causa criminal por el maltratamiento que infirió en mi persona..."

Los caciques siempre eran los señores que tenían medianamente poder, debido a que eran los encargados de dar a la corona la real contribución y única fuente de ingreso de estos servidores de su Majestades, es por ello que agreden o amenazan verbalmente a sus contribuyentes que les deben, pero la con los juicios de limpieza de sangre, y ante una resolución favorable, las condiciones del tributo eran exiguas, además, los mestizos que nacían de madre española y padre indígena les era concedida esta solicitud ante el intendente, ocasionando situaciones inestables para los caciques quienes eran los que al fin y al cabo se enfrentaban con estos casi españoles exentos de la Real contribución y les salían los indígenas descendientes de sangre española quedando eximidos de tal contribución.

Lo mismo paso con los indios forasteros quienes también por juicio de limpieza de sangre quedaban eximidos de tal contribución, esto provocó situaciones de conflictos entre los caciques y tributarios, dándose conatos y protestas sobre todo en la Pampa de Miraflores: lugar donde residían gran cantidad de indios, indios forasteros, plebeyos, artesanos, mestizos; donde las discusiones y amenazas eran constantes debido a que sus habitantes solicitaron su limpieza de sangre y se les concedió; es por ello que lo que dice el cacique Betanzo es cierto:

"Que llegara el día en que todos los indios 
serán españoles".

Esto se debe según a mi entender que los hábitos, costumbres entre los indios y españoles al ser este una plebe plurietnica existe lazos fuertes de hermandad entre las castas. Ignacio de Lecuanda en 1793, al describir el partido de Trujillo decía:

"generalizaba que los españoles son de genio muy dócil y de caridad distinguida y muy cultivados, mientras que los indios todos de un mismo carácter, son incrédulos, desconfiados, recelosos, crueles, en el castigo, ebrios, supersticiosos e incestuosos.( TORD Y LAZO 1981 $\mathrm{V}: 362$.

Entonces podemos inferir, que las castas en una sociedad plurietnica como la arequipeña estaban fuertemente arraigadas en torno a la plebe; pero tenían características definidas muy específicas, a saber:

- Las castas, buscaban tornarse en blancos o españoles por una necesidad económica: la de no pagar tributos.

- Las castas en la ciudad eran tenidas étnicamente como blancos o de manera difusa como claros, lo cual coadyuvaba a presentarse como grupos emergentes socialmente en Arequipa.

- Las castas, en el ámbito rural eran grupos tenidos como en la parte más baja de esa sociedad, lo cual la ciudad prometía mejores condiciones de vida, y es por ello la aparición de una plebe plurietnica más difusa que fija, en cuyo interior eran: Blancos, Cholos, Mestizos, Indios, indios ladinos, forasteros, mulatos y algunos españoles.

\section{V. ¿INMOVILISMO AREQUIPEÑNO?}

Este inmovilismo, señalado por algunos historiadores, consideramos como mal entendido, ya que el referente de esta aceptación y conformismo propiamente es la Arequipa urbana y al interior de ella la elite, en cambio, la plebe como los otros sectores -sacerdotes, intelectuales y jóvenesestuvieron en pro de la patria. Pero donde este fenómeno no tiene asidero, es en el campo donde se observa más claramente; existen enjundiosos estudios de Scarlet O'phelan, Luis Durand Flores, entre otros que han descrito los diversos levantamientos que se dieron en el siglo XVIII, pero tanto los archivos: Arzobispal, Regional como Municipal, tiene bastante información sobre estos hechos:

-Levantamiento de Valderrama, en la revolución de Túpac Amaru.

-Levantamiento de Iglesias en Condesuyos.

-Levantamiento de Bendezu en Chuquibamba.

-Levantamiento de Miguel Bermúdez.

-Movimiento soterrado de Domingo Tristán.

-Apoyo de Fernández de Córdova a la causa de
Pumacahua.

- Apoyo de Centeno y Mariano José de Arce, etc.

Es decir son varios los movimientos asonadas y planes desde el campo por la independencia. Y justamente este es el cuadro donde creemos que la hegemonía ideológica de elite urbana no llegó a persuadir a los espacios rurales de una obsecuencia fidelista, y siendo los elementos de persuasión mínimos además de encontrar explotación y maltrato de criollos y españoles en la zona rural por doquier (Ichuña por ejemplo y los abusos cometidos por el párroco interino don Melchor Rodríguez), este originó levantamientos indígenas liderados para Condesuyos por Fernández de Córdova y Palomino Ángel Figueroa.

Veamos algunos planteamientos al respecto: la idea del indio pasivo y sumiso que se describe en las memorias de los virreyes y que los únicos grandes movimientos fueron los de José Santos Atahuallpa en 1742 y Tupac Amaru, 1780, dándose en un interestadio de cerca de 40 años, una pasividad ecuménica, en la que, algunos historiadores que privilegiaron solo documentación política como fuente primaria: "las memorias de virreyes" y no otro tipo de fuentes como las de carácter fiscal, no encontraron otros movimientos, conatos o insurgencia en los corregimientos; sabemos que en el siglo XVIII , las cargas fiscales se hacen cada vez mas gravosas y lo mismo los repartos de efectos, según Ophelan la incidencia de mayores revueltas se debena:

- Expulsión de los jesuitas creando desajustes en el trabajo hacienda y obrajes.

- Exceso de mercaderías obligados a ser adquiridos por los indios en los famosos repartos, realizado por los corregidores.

- El cobro de diezmos y primicias por la iglesia complementando los tributos e impuestos, llevando al colapso la economía de los indios

- La política tributaria de los Borbones donde se incluyó a mestizos zambos, mulatos y cholos que hasta ese momento estuvieron exentos de tributos. Es menester señalar que para Arequipa los clérigos se dieron cuenta de la conmoción que podía producirse debidos a los repartimientos de efectos realizados por los corregidores (1778) precisan: "debemos temer prudentemente porque pasando de un pueblo a otro el alboroto y rebelión puede llevar la sublevación a mayor parte de este reyno sino se remedia con tiempo".

Creemos entonces que los levantamientos en el surandino del siglo XVIII sobre todo en Arequipa, tuvieron esos considerandos y sobre todo la característica fundamental es la de haber sido rural, con excepción de la rebelión de los pasquines iniciada en Arequipa el 1 enero de 1780, por la abolición de la aduanas y antifiscal, las razones de los otros movimientos presentan características más complejas. Como las diferencias muy marcadas entre 
la jerarquía social, el abuso de los corregidores, el sojuzgamiento de los curas, y toda la política administrativa impuesta por los Borbones como política de recaudación, veamos este cuadro.

\begin{tabular}{|c|c|}
\hline \multicolumn{2}{|c|}{ 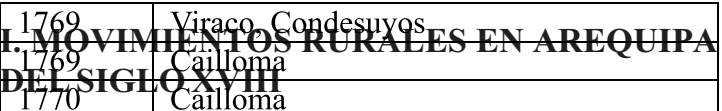 } \\
\hline 1771 & Quechualla, Condesuyos \\
\hline 1773 & Callalli \\
\hline 1775 & Chuquibamba, Condesuyos \\
\hline 1775 & Achoma, Caylloma \\
\hline 1776 & Pampacolca, Condesuyos \\
\hline 1779 & Viraco, Condesuyos \\
\hline 1780 & Arequipa \\
\hline $17 \ldots$ & Belinga, Condesuyos \\
\hline $17 \ldots$ & Puquina, Moquegua. \\
\hline $17 .$. & Majes \\
\hline 1781 & Arequipa \\
\hline
\end{tabular}

Fuente: Biblioteca Nacional de Lima C4129.extraído de Scarlett Ophelan Godoy "Tupac Amaru y las sublevaciones del siglo XVIII," en Sociedad Colonial sublevaciones populares Tupac Amaru II, compilador

\section{PROCESO DE INDEPENDENCIA EN AREQUIPA.}

\section{a) Pumacahua y los hermanos Angulo en Arequipa.}

¿Cuál fue la verdadera actitud de los arequipeños tanto de la elite como de la plebe frente a la rebelión de Pumacahua?, primero aclaremos que es un proceso de casi 45 años de diversos conatos, en la que se nota una actitud de liderazgo indígena inicialmente, es el caso de Túpac Amaru, luego una transición en la rebelión de Pumacahua donde el liderazgo es indígena-criollo y finalmente el liderazgo criollo con las corrientes libertadoras, y todo lo que supuso la independencia. A partir de ello, podemos señalar algunos aspectos: la actividad bélica campesina no tiene sino un valor concomitante, auxiliar o secundario; "puede decirse que halla su expresión máxima en los montoneros"nos diría Basadre; en cambio Charles Walker indica: "que en el montonerismo, el bandolerismo fue una arma letal en la rebelión de Túpac Amaro " (1990). Este hecho propicio Las proclamas en pasquines, lo que Basadre llama " la guerra de papel" en cambio para Quiroz señala el pasquín como el único medio de expresión de protesta en una sociedad muy fuertemente controlada. (1980) Los movimientos conspiradores se hacen notar en Huánuco (1812), Tacna (1813), Cusco (1814) y Tacna (1911), extendiéndose hasta
Arequipa. Basadre las llama a estas conspiraciones, movimientos de la independencia en gestación. (Basadre).Describamos un poco lo acaecido en 1814: A mediados de 1813, al difundirse el avance del ejercito patriota argentino dirigido por Manuel Belgrano (Ejército del Norte), un importante número de notables de Cusco, con el apoyo de oficiales y soldados, del ejercito realistas procedentes de alta y ganados a la causa emancipadora, decidió dejar atrás la defensa de la Constitución española de 1812 contra el absolutismo, asumiendo explícitamente el ideal independentista. Eran líderes de la conspiración los hermanos José, Vicente y Mariano Angulo, Gabriel Béjar, Juan Carbajal y Pedro Tudela, José Vicente Angulo eran oficiales del ejército realista en Abancay, entonces Provincia cusqueña. El primer acto insurreccional se planeó para el 9 de octubre de 1813, contario con el apoyo de los jefes de la guarnición realista del Cusco: Matías Lobatón, Marcelino Vargas. El plan insurgente fue delatado por uno de los firmantes del pacto revolucionario: Mariano Zubizarreta; Los Angulo, Béjar, Carbajal y otros más, fueron arrestados antes de iniciarse las acciones. Los conjurados todavía libres planearon un segundo intento el 5 de noviembre de 1813. Otro traidor, de nombre Mariano Arraiga, fue el causante de un nuevo fracaso. Sin embargo, un grupo de patriotas no cejó en su empeño e intento tomar la plaza mayor cuzqueña, enfrentándose a las tropas leales al virrey José Fernando de Abascal y Sousa, Marques de la Concordia. Murieron tres jóvenes en el intento.

No obstante estar sentenciados a cárcel severa, los líderes de la insurgencia, su ascendiente sobre la población y sobre la guarnición del Cusco consiguió que la vigilancia se debilitara. Pernoctaban en sus casas y dirigían reuniones públicas donde adoctrinaban al pueblo en el ideal patriota. Finalmente en la madrugada del martes 3 de agosto de 1814, hubo un golpe de Estado incruento en el que la guarnición del Cusco se sumo masivamente a los ideales Independentistas. José Angulo asumió el cargo de "capitán general y gobernador político". Según ha investigado José Tamayo Herrera (1984), los jefes militares y las autoridades leales al virrey, fueron confinados en el cuartel general, antiguo convento jesuita y luego, en tiempos republicanos, sede de la Universidad Nacional San Antonio Abad, quedando comprendido dentro de la autoridad de los jefes revolucionarios todo el territorio de la intendencia $\mathrm{y}$, en lo militar, cinco compañías acuarteladas, al mando del comandante Andrés Rendón; un regimiento de dragones al mando del comandante Martín Gabino Concha, " Y grupos efectivos del Regimiento Nacional de Lima. El brigadier Mateo Pumacahua, oficial insurgente de más alta graduación, asumió la jefatura militar revolucionaria.

La proclama de los patriotas del Cusco, firmada ese mismo día, es el primer documento peruano que propone la emancipación, llamando al país a alzarse 
en armas:

"Cuzqueños (..,) todos sois uno e iguales empezad ya a operar con denuedo hollando imperiosamente las leyes bárbaras de España fundaos solo en la necesidad, era la razón y la justicia; y sean estas el timón donde gobernéis a un pueblo que no reconoce autoridad alguna extranjera".

El nuevo gobierno del capitán general, Angulo, nombró plenipotenciarios ante el gobierno independiente de las Provincias de la Plata, recibió parabienes del general Belgrano y procedió a formar sus instituciones. Envió, asimismo, expediciones militares hacia Huamanga, Arequipa y Puno.

El 8 de septiembre de 1814, en la catedral del Cusco, con la bendición del obispo José Pérez y Armendáriz, se rindió culto solemne a una nueva bandera, de franjas transversales azul y blanco, que pudo ser la primera bandera peruana. El 17 de septiembre, José Angulo emitió una "Respuesta peruana al virrey Abascal", en donde le advierte del multitudinario respaldo que tendrá la causa patriota y de lo inútil de hacerle frente mediante las armas:

"Ved virrey (...) Si (...) según es .vuestra fe pública, os ponéis en la triste situación de tratarnos como enemigos, entonces experimentareis nuestro justo rigor, vos y vuestros cómplices. Si, despachad tropas al pasto de nuestra venganza, nosotros os avisarnos que no pasaran de cuatro mil fogueados-valientes militares (...) que contrarrestaran con diez mil que vengan"

La autoridad virreinal limeña, todavía debilitada por la guerra contra la revolución de José Gabriel Condorcanqui (Túpac Amaru II), recién tomo medidas enérgicas en octubre. Mientras tanto, el 29 de agosto los patriotas habían ocupado sin resistencia la ciudad de Puno; otro tanto ocurrió el 20 de septiembre en, Huamanga y el 22 de septiembre en La Paz. Sin embargo, en Arequipa, el mariscal de campo Francisco Picoaga y el intendente José Gabriel Moscoso, con refuerzos llegados desde Lima, se enfrentaron a las tropas de Pumacahua en La Apacheta (Arequipa), el 10 de noviembre de 1814. Con el apoyo de numerosos voluntarios civiles que se fueron sumando desde el Cusco, ganó la causa patriota. Tras esta victoria, la autoridad del capitán general Angulo se extendió hasta la costa.

Una de las proclamas más importante que dieron los revolucionarios a la ciudad de Arequipa, la cito parte de ella, para que se comprenda que el movimiento tenía fuerte adhesión entre los intelectuales, clases populares y un sector eclesiástico, veamos:

Don Mateo pumacahua Mariscal de Campo del ejercito de la patria y Don Vicente Angulo brigadier del mismo ejército.

"y deciros con el lenguaje de la honradez y con la lealtad que acostumbran los hombres de bien. que no temáis, que viváis tranquilos en el goce de que vuestras derechos y posesiones que viváis persuadidos que somos católicos y que respetamos la religión que amamos la humanidad y aborrecemos a los tiranos por tanto debemos de mandar y mandamos y que todas la familias retraidas en los conventos y monasterios se retiren a sus casas a cuidar de ellos seguros de que no serán atropellados.

"que todos los que se hallen con armas oficiales y soldados bien sean espadas, sables, lanzas, pistolas y escopetas, fusiles bocones y cañones, todo armamento y munición de los que se han descarriado en el cuerpo de batalla, en le termino de veinticuatro horas nos lo presentaron so pena de que sus bienes serán confiscados y al que no lo tenga lo pagarla con su cabeza después de ser declarado enemigo de la patria. Que todo empleado del estado que fuere en el término de 24 horas so pena de tratarlo como enemigo de la patria....

Nos indica la necesidad de ordenar la ciudad tomada por los revolucionarios, tratando de ganarse adeptos en los sectores sociales, pero a su vez da garantías a la población de regresar a su casas, ello implica que no toda la población estuvo con los revolucionarios y sobre todo el estamentos del estado, los cuales tenían que entregar las armas so pena considerarlos enemigos de la patria, esta documentación es importante porque precisamente se refiere a la contingencia producida por la posesión de Arequipa, se está halando de lo que pasa en ese momento con la población y los revolucionarios, tenemos un documento muy aleccionador al respecto

\section{Don Mateo García Pumacahua Teniente General de los Ejércitos Nacionales y Mariscal de campo Dr. Vicente Angulo \\ " Por tanto ordenamos y mandamos que dichos prófugos comparezca y que se presenten a esta ciudad y Comandancia General que se restituyan a sus casas en el término preciso y perentorio de quatro días contados desde esta fecha bajo apercibimiento de no cumplir con lo mandado se los declarara contumaces antipatriotas y se procederá a la traba y remate de sus bienes, aplicando al producto de ello para la reposición de sus gastos de esta expedición y demás necesidades de la patria signándoles al efecto este auto y solemne citación.}

Posteriormente Pumacahua se vuelve a pronunciar. Desde la ciudad de Arequipa, el 12 de noviembre de 1814, en representación del gobierno patriota cusqueño, emitiendo una solemne "intimidación" o declaratoria de guerra al virrey Abascal. Sin embargo, al ser informados de las medidas de guerra dispuestas por el virrey; Pumacahua y Angulo decidieron replegarse en torno al Cusco, dejando libres todas las intendencias y provincias ocupadas. ¿Pero cual fue la 
intervención efectiva de los arequipeños en esta Revolución?; Solo por mencionar tenemos la actitud de Mariano José Arce, sacerdote emblemático de la independencia, quien no tuvo reparos en señalar, la abyecta situación de los españoles en esta ciudad, además de morigerar la situación del Rey Fernando VII, como un déspota y Tirano, el encumbramiento de la patria como única forma o razón de ser de una vida digna. Igualmente Corbacho que milagrosamente se salva en Humachiri, la misma suerte no corrió Mariano Melgar, como sabemos fusilado en el campo de batalla.

Las fuerzas del virrey ocuparon la ciudad del Misti el 9 de diciembre de 1814 el general español Juan Ramírez encargado de librar la contraofensiva, aplicó severas penas contra los patriotas arequipeños conocidos. Esto dio lugar a que Angulo dispusiese en el Cusco el fusilamiento de sus dos principales prisioneros de guerra: el mariscal Picoaga y el intendente Moscoso. Para el virrey, esto significo la "guerra a muerte" a los patriotas.

Entretanto, el 8 de febrero de 1815, con representantes de todas las provincias de la intendencia, el ayuntamiento del Cusco ratifico la proclama de agosto.

El "excelentísimo capitán general y gobernador político" José Angulo presto allí el solemne juramento de "amar y defender la patria, no permitir que la ofendan cuanto os pertenezca, ni trabajar contra ella, ni dar lugar a enemigos extraños"

El 12 de febrero, las fuerzas realistas comandadas por Ramírez, partieron de Arequipa con el fin de enfrentarse a Pumacahua y los patriotas. El 11 de marzo, en Umachiri (cerca de Ayaviri, Puno) se dio la batalla decisiva que inclino la balanza a favor de los realistas. No obstante la inferioridad numérica virreinal (1.200 realistas frente a no menos de 12.000 patriotas), venció la disciplina y la mejor habilidad táctica. Una nutrida fuerza conducida por Pumacahua tenía cercados a los realistas con el crecido río Llalli a sus espaldas, mientras del otro lado la artillería patriota les disparaba. Ramírez, audazmente, desmantelo equipos, hizo cruzar el río, con el agua hasta el pecho, a sus mejores tropas desde la otra orilla capturo la artillería peruana y devolvió el ataque, dando tiempo a que el resto de sus fuerzas se enfrentara con ventaja a Pumacahua. En medio del desconcierto causado por esta acción, el general Ramírez dispuso el "ataque a deguello". El parte militar español, firmado el viernes, 12 de mayo de 1815, da cuenta de "siete muertos a bala, seis ahogados en el río y siete heridos" por el lado realista, mientras los muertos patriotas, en su mayoría civiles sin mayor entrenamiento, sumaron más de un millar. Hubo numerosos fusilamientos en el campo de batalla, entre ellos el del poeta arequipeño Mariano Melgar.

El genera! Ramírez ocupo el Cusco el 25 de marzo de 1815. El 21 de abril dispuso las ejecuciones de
Mayorga y de los demás patriotas sobrevivientes: Pumacahua, los hermanos José Vicente y Mariano Angulo, José Gabriel Béjar, Pedro Tudela y otros. El uniforme de José Angulo y su estandarte militar fueron enviados por Ramírez en calidad de trofeos de guerra así concluyó uno de los primeros capítulos a la fiesta emancipadora peruana.

Deben referirse clara y concretamente a lo observado y sin comentarios que signifiquen discusión o interpretación personal de los datos. De ser necesarios, se incluirán tablas y figuras, evitándose toda duplicidad inútil. El modo de presentar las tablas y figuras se describen a continuación

\section{DISCUSIÓN}

Fundamentalmente la actuación de Arequipa en la independencia tuvo dos etapas; el ingreso de Pumacahua a la ciudad, siendo la elite y la plebe que dio algunos signo de adhesión es el caso de algunos intelectuales y clérigos como del cura Mariano José de Arce Y Salamanca, y una segunda propiamente la jura de la independencia en el tardío 1825, pero ello fue en términos urbanos ya que la población rural como se demuestra de la información estuvo en un proceso permanente de asonadas y movimientos.

Los diversos sectores de la población realizaban sus actividades de manera normal evitando que las crisis de independencia perjudicaran sus economías y formas de vida

No hubo mayor movimiento al interior de los grupos tanto en la elite como en la plebe plurietnica y hubo una muy clara decisión por parte de Sucre enviando un oficio en la que se anuncia que la independencia se había logrado en los campos de Ayacucho en un diario la primavera arequipeña.

El sentido patriota o separatista lo asumir pequeños grupos de la ciudad mas no es propiamente la población en términos generales, lo que conlleva a un análisis más prudente sobre el patriotismo y la peruanidad en términos de la memoria historia y el discurso histórico que se expone en las diversas investigaciones

\section{CONCLUSIONES}

La Independencia desde una mirada del proceso regional en Arequipa termina teniendo particularidades en torno a tres aspectos, el espacio surandino aislado respecto de la capital y el norte, la fisonomía de la plebe y la elite arequipeña, donde estaban premunidos por el honor la nobleza y un conjunto de valores estamentales.

La independencia en Arequipa no fue un proceso que de manera determinante busco su libertad sino más bien por el contrario la elite y parte de la población 
realizó diversas donaciones para la gesta realista.

Los hechos más importantes de la intervención en la independencia de esta ciudad, son los referidos al ingreso de Pumacahua y la jura de la independencia en 1825, después de la derrota de los realistas en Ayacucho.

La propuesta patriótica de Arequipa sobre la independencia perteneció a un grupo pequeño de intelectuales, sacerdotes y parte de la población que en si no tuvo mayor connotación, pero que convertido en discurso histórico se insuflan las acciones de estos personajes.

\section{REFERENCIAS BIBLIOGRÁFICAS}

Anna, T. (2003). Caida del Gobierno español en el Perú. Lima: IEP.

Belaunder, V. A. (1957). La cuestión social en Arequipa, En: Prosistas e historiadores. Arequipa: Lumen.

Bonilla, H. y. (1981). Independencia en el Perú. Lima: IEP.

BRIAN R. HAMNETT. (2011). Revolución $y$ contrarrevolución en México y el Perú. Liberales, realistas y separatistas, 1800-1824, . México D.F: Fondo de Cultura Económica, .

Chambers, S. (1991). Los matices de la ciudad Blanca: la sociedad urbana en Arequipa 1780-1854. Arequipa: Inedito.

Chambers, S. (2003). De subditos a ciudadanos: Honor género y politica en Arequipa. 1780/1854. Lima: Pucp.

CNSIP. (1971-1976). Colección docue ¿mental de la independe4ncia del Perú. Lima: CNISP.

De la Puente y Candamo, A. (2013). Independencia del perú. Lima: Fondo del Congreso de la República.

Fisher, J. (1968). Arequipa 1796.1811. Lima: UNMSM.

Flores-Galindo,A. (1977). Arequipa y el sur andino. Lima: Horizonte.

Guerra, F.-X. (1992). Modernidad e independencias. Madrid: MAPFRE.
LAZO, T. Y. (1981). Historia del Perú. T IV. Lima: Juan Mejía Baca.

Leguia, G. (1972). Historia de la emancipación del Perú: el protectorado. 7 vols. Lima: CSIP.

Paz-Soldan. (1888). Historia del Perú Independiente. Lima: Lemale.

Vickuña, B. (1971). Independencia en el Perú. Buenos aires: Aguirre.

Zegarra Meneses, G. (1973). Arequipa en el paso de la colonia a la república. Arequipa: Cuzzi. 